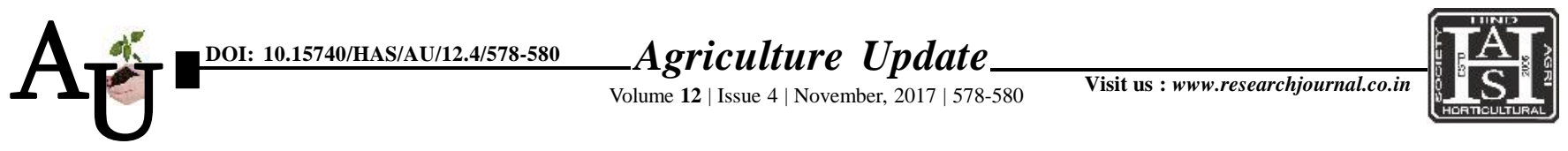

ש e ISSN-0976-6847

\title{
Research article: Constraints faced by the Naga King chilli gowers in Mokokchung district of Nagaland
}

\section{PIJUSH KANTI BISWAS, KERIMENLA AND RAJIB DAS}

Article Chronicle: Received :

19.07.2017;

Revised :

30.08.2017;

Accepted :

16.09.2017

KEY WoRDS :

Naga King Chilli,

Problems, Post

harvest storage
Author for correspondence :

\section{PIJUSH KANTI BISWAS}

Krishi Vigyan Kendra, MOKOKCHUNG

(NAGALAND) INDIA

Email:drpijushpckvk@

gmail.com

See end of the article for authors' affiliations
SUMMARY : The ex-post facto study was conducted in Mokokchung district of Nagaland to know the problem faced by the Naga King Chilli growers in Mokokchung district of Nagaland". Further 140 farmers were selected from different villages in two different blocks under Mokokchung. Results revealed from the study that lack of proper post harvest storage of Naga King chilli $(90.00 \%)$ was found the most problematic area faced by majority of the Naga King chilli growers.

How to cite this article : Biswas, Pijush Kanti, Kerimenla and Das, Rajib (2017). Constraints faced by the Naga King chilli gowers in Mokokchung district of Nagaland. Agric. Update, 12(4): 578-580; DOI : 10.15740/HAS/ AU/12.4/578-580. 